\title{
APPLICATION OF KARYOTYPING AND FLOURESCENT IN SITU HYBRIDISATION IN DETECTION OF KLINEFELTER SYNDROME
}

\section{Anjali Shastry ${ }^{* 1}$, Preetha Tilak ${ }^{2}$, Amudha Subramaniam ${ }^{3}$.}

${ }^{{ }_{1}}$ Tutor, Department of Anatomy, St Johns Medical College, Bangalore, Karnataka, India.

2 Junior consultant, Department of Anatomy, St Johns Medical College, Bangalore, Karnataka, India.

${ }^{3}$ Tutor, Department of Anatomy, St Johns Medical College, Bangalore, Karnataka, India.

\section{ABSTRACT}

Introduction: Klinefelter Syndrome is one of most common sex chromosomal abnormality in males with incidence of 1 in 600 live births. Fluorescence in situ hybridization (FISH) is a powerful molecular cytogenetic technique which allows rapid detection of aneuploidies on interphase cells and metaphase spreads along with conventional GTG banding technique.

Aims and objectives: To evaluate application of karyotyping and FISH as important diagnostic tool in diagnosis Klinefelter Syndrome.

Materials and Methods: A retrospective study was conducted on 44 patients who were referred for karyotyping and counselling with suspected Klinefelter Syndrome and hypogonadism to Division of Human Genetics, Department of Anatomy, St. John's Medical College, Bangalore from January 2014 to October 2017. Chromosomal preparations were done using the peripheral lymphocyte culture method followed by GTG banding technique, automated photography and karyotyping.

FISH was performed with dual colour X/Y probes once abnormality was detected using GTG banding technique. Results: Out of 44 patients, 9 had typical karyotype of Klinefelter syndrome $(47, \mathrm{XXY})$ and Four had variants of Klinefelter syndrome

Conclusion: We can conclude that cytogenetic analysis forms important investigation in diagnosis, treatment and fertility status in patients with Klinefelter syndrome.

KEY WORDS: Fluorescence in situ hybridization (FISH), Klinefelter Syndrome, Sex chromosome, Cytogenetic technique.

Address for Correspondence: Dr. Anjali Shastry, Tutor, Department of Anatomy, St Johns Medical College, Bangalore, Karnataka, India. E-Mail: anju_shas@yahoo.com Journal Information

\section{Quick Response code}

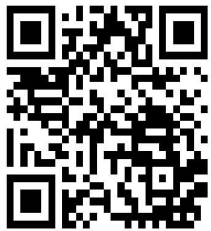

DOI: $10.16965 /$ ijar.2018.310

\begin{tabular}{|c|c|c|}
\hline \multicolumn{3}{|c|}{ Journal Information } \\
\hline \multicolumn{3}{|c|}{ 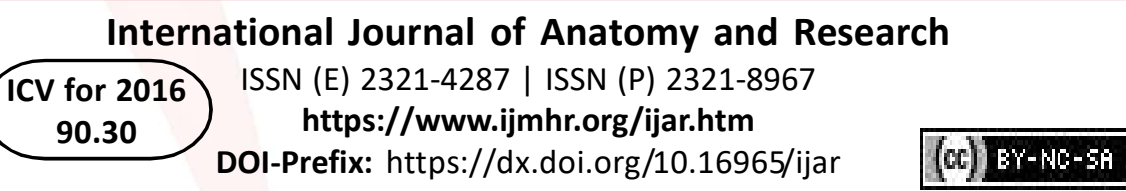 } \\
\hline \multicolumn{3}{|c|}{ Article Information } \\
\hline $\begin{array}{l}\text { Received: } 06 \text { Jul } 2018 \\
\text { Peer Review: } 06 \text { Jul } 2018 \\
\text { Revised: None }\end{array}$ & $\begin{array}{l}\text { Accepted: } 13 \text { Aug } \\
\text { Published (O): } 05 \\
\text { Published (P): } 05\end{array}$ & $\begin{array}{l}18 \\
2018 \\
2018\end{array}$ \\
\hline
\end{tabular}

\section{INTRODUCTION}

Klinefelter Syndrome is one of most common sex chromosomal abnormality in males with incidence of 1 in 600 live births. Klinefelter syndrome (KS) was first described by Harry F. Klinefelter in 1942 in 9 men with testicular abnormalities who failed to produce sperm and had gynecomastia. About $80 \%$ of KS patients show a $47, X X Y$ karyotype, $20 \%$ have other numeric sex chromosome abnormalities (48,XXXY, 48,XXYY, 49,XXXXY), 46,XY/47,XXY mosaicism, or structurally abnormal sex chromosome. Frequency of 48,XXXY \& 48,XXYY is around 1 in 17000 to 1 in 50000 male births and frequency of $49, X X X X Y$ being 80,000 to 
$1,00,000$ live births [1]. The typical symptoms are a tall stature, narrow shoulders, broad hips, sparse body hair, gynecomastia, small testes, absent spermatogenesis, normal to moderately reduced Leydig cell function, increased secretion of follicle-stimulating hormone, androgen deficiency, and normal to slightly decreased verbal intelligence. Apart from this they can present with osteoporosis, varicose veins, thromboembolic disease, or diabetes mellitus. With a frequency of $4 \%$, KFS is described to be the most common genetic reason for male infertility. Cytogenetic analysis is necessary to make a definite diagnosis of Klinefelter Syndrome, and more obvious differences in physical features tend to be associated with increasing numbers of sex chromosomes. In addition to this FISH forms a rapid tool to identify marker chromosome as well as hidden mosaicism in both metaphase spreads and interphase nuclei.

Aims and objectives: To evaluate application of karyotyping and FISH as important diagnostic tool in detecting and confirming sex chromosomal abnormalities in males with suspected Klinefelter syndrome.

\section{MATERIALS AND METHODS}

A retrospective study was conducted on 44 patients who were referred for karyotyping and counselling with hypogonadism and primary infertility to Division of Human Genetics, Department of Anatomy, St. John's Medical College, Bangalore from January 2014 to October 2017. Chromosomal preparations were done using the peripheral lymphocyte culture method followed by GTG banding technique, automated photography and karyotyping.

FISH was performed with $X / Y$ probes once abnormality was detected using GTG banding technique.

\section{RESULTS}

Table 1: Karyotype of Males suspected with Klinefelter Syndrome.

\begin{tabular}{|c|c|c|c|}
\hline $\begin{array}{l}\text { Total number } \\
\qquad(n=45)\end{array}$ & $\begin{array}{c}\text { Normal Karyotype } \\
\qquad(\mathrm{n}=31)\end{array}$ & $\begin{array}{c}\text { Typical karyotype } \\
\text { of KFS (n=9) }\end{array}$ & Klinefelter variants $(n=5)$ \\
\hline Karyotype & $46, X Y$ & $47, X X Y$ & $\begin{array}{c}448, \mathrm{XXYY} \\
\operatorname{mos} 47, \mathrm{XXY} / 46, \mathrm{XY} \\
\operatorname{mos} 47, \mathrm{XXY}[33] / 48, \mathrm{XXY},+\operatorname{mar}[17] \\
49, \mathrm{XXXXY} \\
47, \mathrm{XXY}, \mathrm{t}(1: 4)(\mathrm{q} 24 ; \mathrm{q} 28)\end{array}$ \\
\hline
\end{tabular}

Out of 45 patients 9 had typical karyotype of Klinefelter syndrome $(47, X X Y)$ and 5 had variants of Klinefelter syndrome.

Fig. 1: 19 yrs old male who presented with hypogonadism FSH, LH - increased and decreased testosterone levels. Karyotype (Fig 2a) 47XXYY. Metaphase spread (Fig1b) showing 2 green $(X) \& 2$ red $(Y)$ signal.

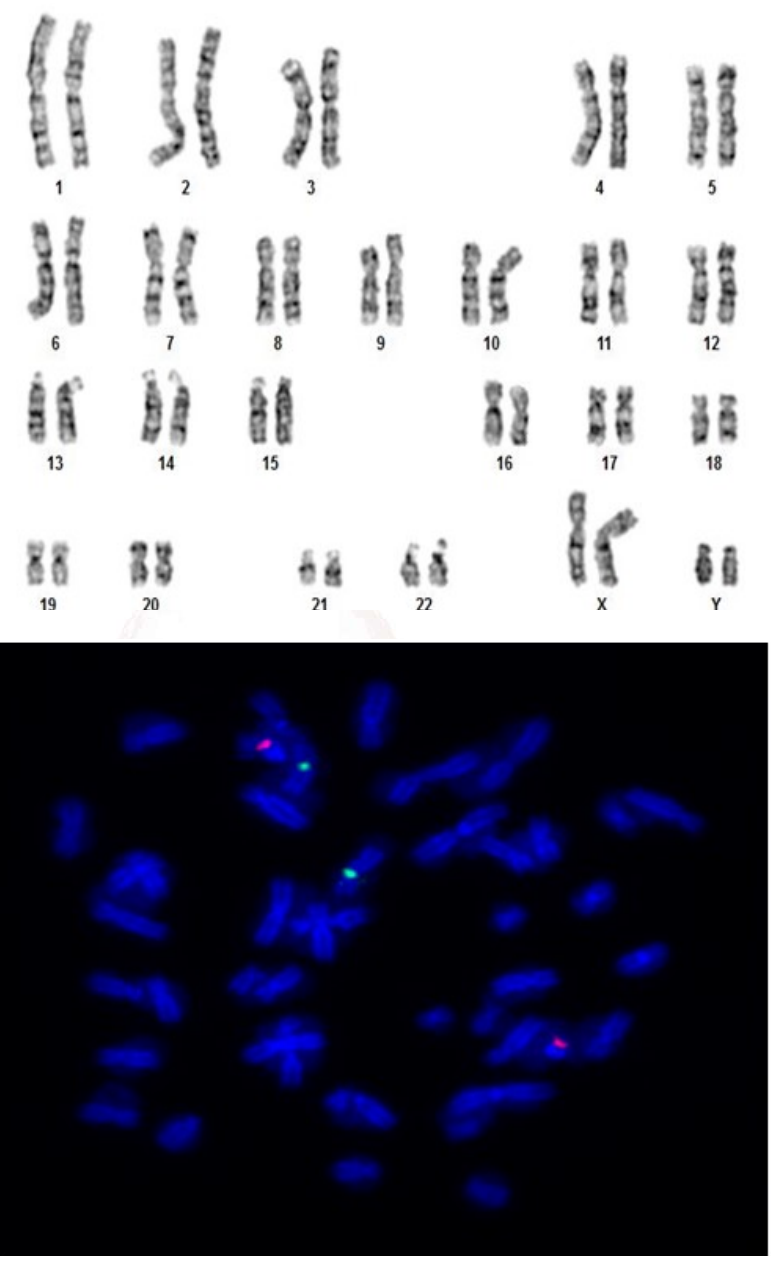

Fig. 2: 3 yrs 2 months old child, born to a non consanguineous couple was referredfor karyotyping with history of developmental delay, speech delay, short stature, telecanthus, bilateral low set ears, small mouth, gen velgum, flat feet, valgus deformity, bil broad toes, proximally placed thumb ( $r$ hand), Simian crease (left hand). Karypotype (fig 2) showed 49 XXXXY.

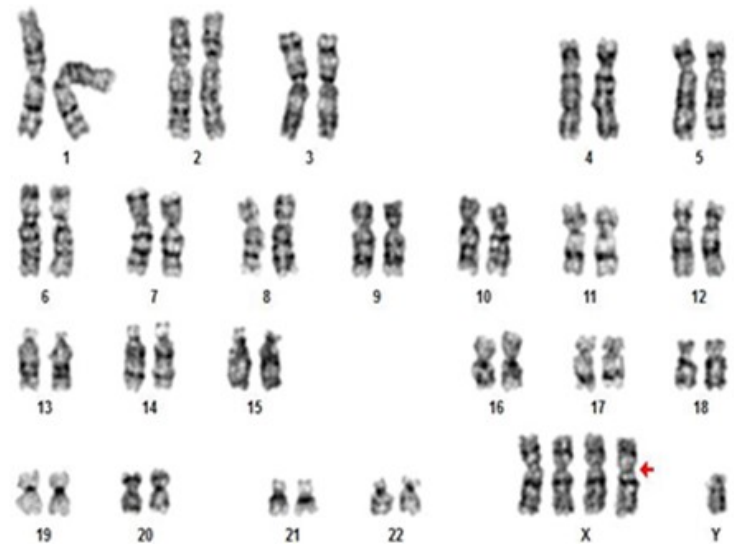


Fig. 3: 38 yrs old male, married (consanguineous) for 13 years referred for karyotyping with history of primary infertility on examination he has hypogonadism and semen analysis showed Azoospermia/Crypto-Zoospermia. Karyotype (3a) was 47 XXY [33]/48 XXY + mar [17] suggestive of klinefelter syndrome. Metaphase (4b) FISH showing 2 green $(X) \& 1$ red $(Y)$ signal. In high SKY (\#c) Marker got confirmed derivatives of chromosome 5.

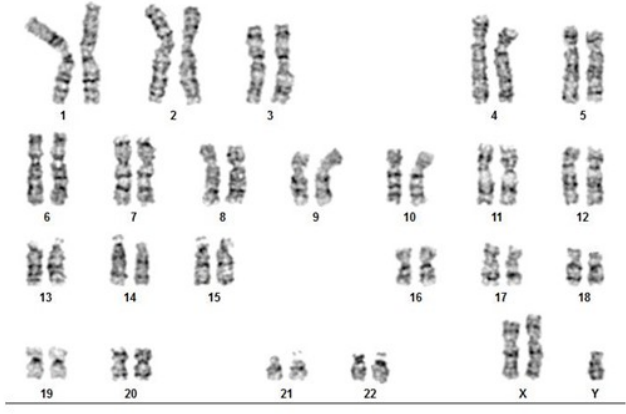

$4 a$

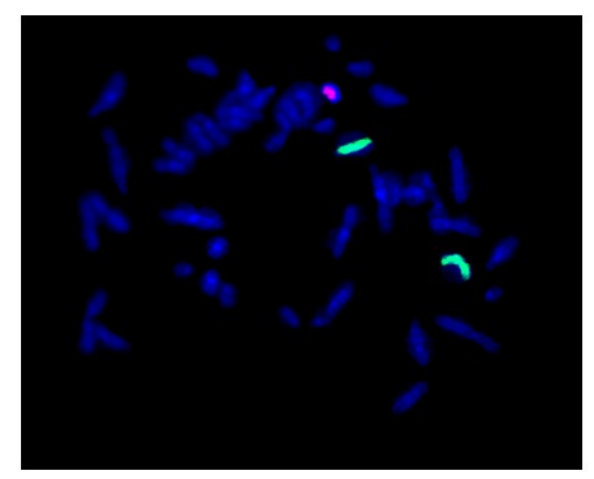

\section{DISCUSSION}

Klinefelter syndrome occurs due to meiotic non disjunction during gametogenesis of egg and sperm. Studies have suggested that there is a significant increase in risk for $47, \mathrm{XXY}$ live births with advanced maternal age. Mandoki et al., reviewed current knowledge of the genetic and endocrinological characteristics of KFS as well as the psychological functioning of XXY males in childhood and adolescence. [2] Fruhmesser et al., did systematic review study on more than 300 articles with reference to Klinefelter syndrome [3]. They concluded that the effects on physical and mental development increase with the number of extra $X$ chromosomes, and each $X$ reduces the overall IQ by 15-16 points, with language most affected. In addition, it was found that height decreases and radioulnar synostosis becomes more frequent as the number of $X$ chromosomes increases. Demirhan et al., studied frequency and types of chromosomal abnormalities in males with hypogonadism [4]. They found that most common cause of hypogonadism was Klinefelter syndrome and its variants (14.1\%).In Indian study done by Gajanan et al., on 30 azoospermic males $10 \%$ had $47, X X Y$
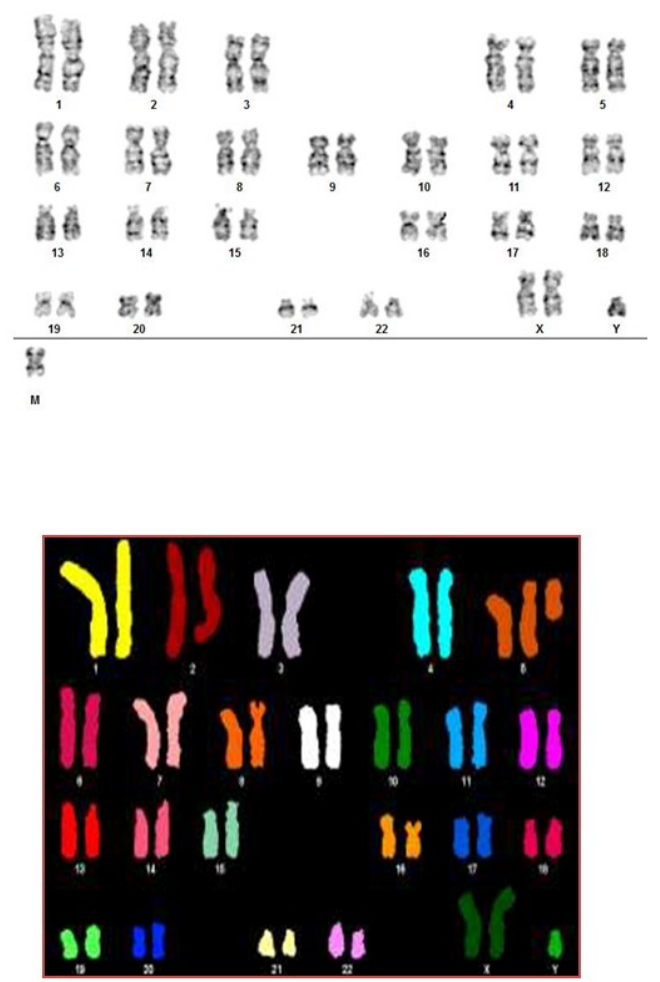

Karyotype [5]. Kaathleen Hwang et al., did FISH analysis on sperms of infertile males and information gathered from sperm FISH can enhance reproductive counseling, guide clinical management in family planning, and determine the need for PGD [6].

Karimi et al., reported a rare case of Klinefelter Syndrome Patient with Quintuple Mosaic Karyotype 47,XXY/46,XX/ 45,X/48,XXXY/ 46,XY mosaicism. The predominant cell line was $47, X X Y$ (83.67\%). This was confirmed by fluorescence in situ hybridization (FISH) [7].

Hanley et al., studied MRI of brain in 25 males with 48,XXYY syndrome.They concluded that XXYY group had a higher incidence of colpocephaly, white matter lesions and thin posterior body of the corpus callosum [8]. The specificity of these findings may shed light on the role of the $X$ and $Y$ chromosomes in typical and atypical brain development and help provide direction for future studies of brain-behavior relationships in males with XXYY syndrome.

Peet J et al., reviewed three cases of $49, X X X X Y$ syndrome and came to a conclusion that presence of phenotype consisting of a characteristic facies and habitus, multiple skeletal 
anomalies, cardiac defects, genital abnormalities, a variable degree of mental impairment, and severe speech impairment apartment from classic triad of 49,XXXXY syndrome (mental retardation, radioulnar synostosis, and hypogonadism) distinguishes it from Klinefelter Syndrome [9]. Jonathan et al., did comparative study of brain of 49, XXXXY individuals with healthy individuals [10]. There was substantial reduction of brain volume and more evidence of white matter abnormalities in individuals with $49, X X X X Y$ syndrome when compared with healthy individuals. They concluded that increased dosage of genes on $X$ chromosome had substantial effects on development of white matter of brain.

Hence karyotyping and FISH will not only help in detection of Klinefelter syndrome and its variants but also helps understanding role of $X$ chromosome in predisposing these patients to various other medical disorders. It might also help in deciding infertility treatments to these individuals.

\section{CONCLUSION}

We can conclude that cytogenetic analysis forms important investigation in diagnosis, treatment and fertility status in patients with Klinefelter syndrome.

\section{ACKNOWLEDGEMENTS}

We thank staffs of division of human genetics. We also thank Centre for Human genetics, Bangalore for High SKY report.

\section{Conflicts of Interests: None}

\section{REFERENCES}

[1]. Visootsak J, Graham JM. Klinefelter syndrome and other sex chromosomal aneuploidies. Orphanet J of Rare Dis. 2006;1:42.

[2]. Mandoki MW, Sumner GS, Hoffman RP, Riconda DL.A review of Klinefelter's syndrome in children and adolescents. J Am Acad Child Adolesc Psychiatry. 1991 Mar;30(2):167-72.

[3]. Fruhmesser A, Kotzot D. Chromosomal variants in klinefelter syndrome. Sex Dev. 2011;5(3):109-23.

[4]. Tartaglia N, Ayari N, Howell S, D'Epagnier C, Zeitler P. 48,XXYY, 48,XXXY and 49,XXXXY syndromes: not just variants of Klinefelter syndrome. Acta Paediatr. 2011 Jun;100(6):851-60.

[5]. Hanley, A. P., Blumenthal, J. D., Raitano Lee, N., Baker, E. H., Clasen, L. S., \& Giedd, J. N. Brain and behavior in 48, XXYY syndrome. Neurolmage/ Clin, 2015;8:133-139.

[6]. Hwang, K., Weedin, J. W., \& Lamb, D. J. The use of fluorescent in situ hybridization in male infertility. Therapeutic Advances in Urology, 2010;2(4), 157-169.

[7]. Karimi H, Sabbaghian M, Haratian K, Vaziri Nasab H, Farrahi F, Moradi SZ, Tavakolzadeh T, Beheshti Z, Gourabi H, Meybodi AM.A Rare Case of Klinefelter Syndrome Patient with Quintuple Mosaic Karyotype, Diagnosed by GTG-Banding and FISH. Int J Fertil Steril. 2014 Jul;8(2):221-4. Epub 2014 Jul 8.

[8]. Maske GL, Kannamwar AD. Klinefelter's syndrome in azoospermic infertile males of Vidarbha region, Central India. Int J Res Med Sci 2016;4:1045-50.

[9]. Peet, J., Weaver, D. D., \& Vance, G. H. (1998). 49, XXXXY: a distinct phenotype. Three new cases and review. Journal of Medical Genetics, 1998;35(5):420-424.

[10]. Blumenthal JD, Baker EH, Lee NR, Wade B, Clasen LS, Lenroot RK, Giedd JN.Brain morphological abnormalities in 49,XXXXY syndrome: A pediatric magnetic resonance imaging study. Neuroimage Clin. 2013;2:197-203.

How to cite this article:

Anjali Shastry, Preetha Tilak, Amudha Subramaniam. APPLICATION OF KARYOTYPING AND FLOURESCENT IN SITU HYBRIDISATION IN DETECTION OF KLINEFELTER SYNDROME. Int J Anat Res 2018;6(3.3):5682-5685. DOI: 10.16965/ijar.2018.310 